\title{
Distribution and fractionation of REEs during ferrihydrite transformation
}

MeIJUN YANG ${ }^{1}$, XiAOLIANG LiAng ${ }^{2}$, HONGPING He ${ }^{3}$ YUJI ARAI $^{4}$

${ }^{1}$ Guangzhou Institute of Geochemistry, Chinese Academy of Sciences, Guangdong, 510640, PR China (yangmeijun@gig.ac.cn)

${ }^{2}$ Guangzhou Institute of Geochemistry, Chinese Academy of Sciences, Guangdong, 510640, PR China (liangxl@gig.ac.cn)

${ }^{3}$ Guangzhou Institute of Geochemistry, Chinese Academy of Sciences, Guangdong, 510640, PR China (*correspondence: hehp@gig.ac.cn)

${ }^{4}$ Department of Natural Resources and Environmental Sciences, University of Illinois at Urbana-Champaign, Illinois, 61801, USA (yarai@illinois.edu)

Ferrihydrite is ubiquitous in low-temperature geochemical environments and act as an effective REE carrier. Its transformation significantly influence the occurrence and distribution patterns of REEs as they dissolve or substitute $\mathrm{Fe}$ in lattice due to structure alteration. However, the sequestration of REEs by its transformation products such as goethite and hematite has not been extensively investigated.

Herein, the series of REE(III) (La, Ce, Pr, Nd, Sm, Eu, $\mathrm{Gd}, \mathrm{Tb}, \mathrm{Dy}, \mathrm{Ho}, \mathrm{Er}, \mathrm{Tm}, \mathrm{Yb}, \mathrm{Lu}$, and Y) was coprecipitated at a Fe:REE ratio of 100:3 during the synthesis of 2-line ferrihydrite at $\mathrm{pH} 5$ and 7, forming REE substituted/sorbed ferrihydrite. To facilitate the transformation of ferrihydrite, the solids were then aged for 90 days at $40{ }^{\circ} \mathrm{C}$. Changes in mineralogy, morphology, and REE sorption/substitution were evaluated using XRD, ICP-MS, TEM, and Mössbauer spectroscopy.

Due to its smaller ionic radii, more heavier REEs were sequestered by iron oxides than lighter REEs. The degree of REE sorption/isomorphous substitution was also pHdependent. At $\mathrm{pH}$ 5, ferrihydrite was transformed into goethite and hematite via dissolution-recrystallization and aggregation-recrystallization, respectively. During the transformation, the structural substitution of REEs was reduced, elevating the concentration of $\operatorname{REE}(\mathrm{aq})$. At $\mathrm{pH} 7$, ferrihydrite particles aggregated and effectively entrapped REEs within the structure. Approximately $20-30 \%$ of REEs were incorporated in the structure of hematite after 90 days. The results should be of interest to geochemists to better understanding and mastery of geochemical behaviors of REEs in Fe geochemcial cycles. 